\title{
The influence of olfactory cues on exploratory behavior '
}

\author{
M. S. HALLIDAY ${ }^{2}$ \\ UNIVERSITY OF SUSSEX
}

Short-term changes in exploratory activity of rats in simple mazes might be a result of olfactory changes in the maze, during intervals between trials. An experiment is reported in which olfactory changes were deliberately introduced in the interval between two brief exploratory trials, but these changes did not alter exploratory behavior on the second trial. It is concluded that olfactory cues probably play a relatively minor role in the control of exploratory behavior.

In a previous study (Halliday, 1967) it was found that if satiated rats were given two 3-min trials in which to explore an elevated $Y$-maze, their activity on the second trial was a function of the length of the interval between trials. If this intertrial interval was as short as $45 \mathrm{sec}$, activity on the second trial was only about $25 \%$ of that on the first trial. With longer intervals, second trial activity increased and was equal to first trial activity with intertrial intervals as short as $10 \mathrm{~min}$. Similar results were obtained using an enclosed $\mathrm{Y}$-maze, but recovery of activity on the second trial was not complete at any intertrial interval up to $5 \mathrm{~h} 20 \mathrm{~min}$. These results might be attributed to the recovery of novelty of the maze during the intertrial interval (e.g., Berlyne, 1960; Montgomery, 1953), though such a suggestion implies a very fast rate of forgetting, and alternative explanations are possible (Halliday, 1966).

It is possible, however, that these changes in exploratory activity on the second trial were the result of changes in the maze, and not of processes in the rat. In the experiments mentioned above, every attempt was made to keep the intra- and extra-maze visual stimuli constant between trials, extraneous auditory signals were masked by white noise, and the tactual characteristics of the mazes could hardly have varied between trials. It is possible, however, in view of the rat's well known olfactory capacities, that the olfactory environment differed markedly from trial to trial. The mazes were wiped out with a damp cloth between trials, but this precaution may not have been adequate; after a delay of $10 \mathrm{~min}$, during which other animals were run in the maze, the rats may have found themselves in what was effectively a novel, or least considerably changed, olfactory environment. If this were so, olfactory changes deliberately introduced between trials should increase exploratory activity on the second trial with intertrial intervals of less than $10 \mathrm{~min}$. The present experiment was performed to test this possibility. Method

The Ss were 30 naive female hooded rats about
100 days old. Ss were housed, four to a cage, in wire mesh cages, and had ad lib access to food (laboratory chow) and water.

The apparatus was an elevated maze with three hardboard arms meeting at $120 \mathrm{deg}$; each of these arms was $18 \mathrm{in.}$ long $\mathrm{x} 4 \mathrm{in.}$. wide, and $18 \mathrm{in.} \mathrm{above}$ floor level. The maze was placed in an enclosure, $4 \mathrm{ft} 6$ in. $\mathrm{x} 4 \mathrm{ft} 6$ in. $\mathrm{x} 4 \mathrm{ft}$ high, which was covered with black curtain material. The enclosure was lighted by a single $100 \mathrm{~W}$ bulb, suspended centrally 6 in. from the top. Ss could be observed through a screened aperture in one side of the enclosure. A white noise of moderate intensity masked sounds from outside the experimental room.

Ss were given two days of pretraining, during which they were left to move around in a $3 \mathrm{ft}$ square enclosure with metal walls for $10 \mathrm{~min}$ a day; they were picked up and handled from time to time.

On the third day, Ss were randomly divided into three groups of 10. They were then all given two exploratory trials in the Y-maze. On each trial the $S$ was placed at the end of one arm of the maze and allowed to explore for $3 \mathrm{~min}$. Each arm of the maze was divided by a line on the floor into two 9-in. sections, and records of S's entries to these sections were made for each $30 \mathrm{sec}$ of the trial. At the end of $3 \mathrm{~min}, \mathrm{~S}$ was removed from the maze, put in a metal delay cage, and left there for $1-1 / 2 \mathrm{~min}$. It was then given a second trial on the elevated maze and returned to its home cage. The differences between groups were in the treatment of the maze between trials: (1) Group 1-no change between trials; (2) Group 2-the maze was wiped out with a damp cloth smelling strongly of disinfectant between trials; (3) Group 3-a decoy rat from a different home cage was forced to run along all the arms of the maze during the delay.

\section{Results}

The mean number of section entries for each group on each trial are shown in Table 1. No difference between any pair of groups on either trial were significant (t tests). Nor were there significant dif-

Table 1.

Mean number of section entries for each group on each trial.

Trial 1.

Trial 2

\begin{tabular}{ccc} 
& Trial 1. & Trial 2. \\
\hline Group 1 & 14.8 & 7.7 \\
Group 2 & 15.2 & 6.2 \\
Group 3 & 15.0 & 8.33 \\
\hline
\end{tabular}


ferences in activity between groups in any of the 30 sec intervals into which each trial was subdivided. The decrease in activity between trials was significant for all groups ( $p<.05$ in all cases, sign test), and was of about the size to be expected from previous work (Halliday, 1967).

Discussion

The results give no support to the suggestion that recovery in exploratory activity between trials is a result of changes in olfactory stimulation within the maze. Any changes occurring naturally during a 10 min delay could only be small compared to the changes deliberately introduced in the present experiment, which failed to produce increases in exploratory activity on the second trial. It also appears that despite the rats' sensitivity to olfactory stimuli, such stimuli probably play only a minor role in the control of exploratory behavior.

References

BERLYNE, D. E. Conflict, arousal and curiosity. New York: McGrawHill. 1960.

HALLIDAY, M. S. The effects of variation of intertrial interval on exploration of elevated and enclosed mazes. Quart. J. exp. Psychol, $1967,19,264271$.

HALLIDAY, M. S. Exploration and fear in the rat. Symp. Zool. Soc., Lond., 1966, No. 18, 45-59.

MONTGOMERY, K. C. Exploratory behavior as a function of "similarity" of stimulus situations. J. comp. physiol. Psychol, 1953, 46, 315-319.

Note

1. This experiment was carried out at the Psychological Laboratory, Cambridge, while the author held a Training Research Grant from the Medical Research Council.

2. The author is grateful to Mr. A. J. Watson for his help and encouragement. 